\title{
THREE-DIMENSIONAL MODELLING FOR REINFORCED CONCRETE BEAMS WITH OPENINGS BASED ON NONLINEAR ELASTIC-DAMAGE THEORY
}

\author{
H. Madkour ${ }^{1}$, K. AHMED ${ }^{2}$ \\ ${ }^{1}$ Civil Engineering Dept., South Valley University, EGYPT, 81542, Aswan \\ ${ }^{2}$ Civil Engineering Dept., University of Assiut, EGYPT, Assiut \\ hrmadkour@yahoo.com, kamaelsadek@yahoo.com
}

(Received October 28, 2006 Accepted November 29, 2006)

\begin{abstract}
The objective of this paper is presenting a new three-dimensional nonlinear elastic damage theory for simulating reinforced concrete elements. More attention was devoted for simulating of the nonlinear behaviour of the reinforced concrete beams with opening based on rigorous thermodynamic basis. The new developed theoretical approach takes into consideration the nonlinear elastic behaviour and the deteriorated state of the concrete materials. Finally, the introduced nonlinear concrete model is verified by various numerical simulation of experiments carried out in order to analyze the proposed behaviour of reinforced concrete beams under monotonic static loading. A comparison with experimental results available in literature is performed in order to validate the proposed model. A very good agreement was achieved.
\end{abstract}

\section{KEYWORDS: Nonlinear elastic; Damage; Reinforced concrete beams; Openings}

\section{INTRODUCTION and BACKGROUND}

The behaviour of reinforced concrete element depends on the combined action of the concrete (damaged state and the mechanical properties), its embedded reinforcement and the features of the element (existing openings), as well. Hardened concrete itself, predominantly a mixture of aggregates and a cementitious matrix, exhibits rather complicated deformation behaviour, mainly because of initiation and growth of microcracking in the matrix.

Cementitious materials like concrete are characterized by a nonlinear response with different strength in compression and tension. In particular, experimental results showed that these materials present brittle behaviour in tension and inelastic deformations accompanied by damage effects in compression. The crucial point of the study of the mechanical behaviour of cementitious structures is the definition of proper constitutive law and of a suitable model able to reproduce the s tructural response of 
reinforced concrete elements. Constitutive models for concrete exist on very different quality levels. The most advanced structural codes of practice offer mainly elastic behaviour, without any mechanical specification. On the other (research) extreme, we find highly sophisticated constitutive attempts with few relations to engineering design practice. Obviously in constitutive modeling of concrete, an elastoplastic modelling has to be combined with damage state. Hence the key aim here is introducing a 3dimensional nonlinear elastic damage description of mechanical responses of reinforced concrete, supplemented by a damage concept.

Nowadays, many reinforced concrete structures, particularly industrial and office buildings require a large number of mechanical installations and pipelines for heating, ventilation, air conditioning....etc. One of the most conventional ways to perform these installations is to create openings in the webs of the beams. Previous analyzing for reinforced concrete beams with openings, basically based on simplified methods to calculate fairly accurate values of straining actions for dimensioning and detailing of beams with openings. Among this literature, Mohamed [1] considered a rigid frame in the plane of the beam consisting of the parts enclosing the openings and totally fixed in the remainder of the beam. The solution is based on the assumption that plain sections normal to the centerline of the beam remain plain and normal to it after bending. Nasser et al. [2] treated the problem of rectangular openings in the web of the beam considering the top and bottom chords of the opening to behave similar to the chords of a vierendeel panel. In their study, they assumed that the cross members provided with adequate stirrups carry the external shear in proportion to their cross-sectional areas. Also, they assumed that the cross members of the openings have contra flexure points at mid-span when they are not subjected to transverse loads. Hamdy [3] studied the behaviour of R.C beams with end rectangular openings. He used the finite element method to determine the elastic deformations and the internal stresses. The obtained results from the analytical solution were verified experimentally. From the test results, he concluded that the provision of end rectangular opening in the shear zone of R.C beams increases the deflection, reduced the cracking and ultimate loads, changes completely the distribution of the stresses in the end of the beam and changes the mode of failure. Also, he concluded that as the opening dimension increases, the central deflection and the elastic stress also increases, while the opening location along the beam axis has no effect. Nassef et al. [4], studied the effect of end opening in rectangular. The test results showed that, rectangular openings with fillet corners and diagonal steel bars improved the crack distribution around the corners of the openings and increased the shear strength of the beams nearly equal to those corresponding to beams without openings. Mansour et al. [5], proposed a theoretical method for predicting surface load deflections of R.C beams that contain a large web openings. The author assumed that the connecting cord members are replaced by an equivalent continuous medium and the beam can be considered as a structural member comprising a number of uniform segments. In 2003, Moussa et al. [6] have introduced experimental and two dimensional numerical investigations for R.C. deep beams with and without openings. It has been concluded that the presence of openings affects the behaviour, shear and flexural capacities and strength of reinforced concrete deep beams. This effect depends mainly on the size, location and distribution of openings. Finally, it is worth to mention that, it was not attempted in these methods to obtain the 
exact stresses around the openings or evaluate the ultimate stresses corresponding to the failure state.

Finite Element Methods (FEM) based on local analysis theories such as fracture mechanics suffer from strong mesh-dependency. Also, it was observed that the socalled size effect of structures cannot be simulated by local models. The reason for these difficulties lies in the fact that material degradation during the lifetime of structures is governed by physical mechanisms on levels with different length scale, (macro- and meso- or microlevel). Generally, local analysis is mainly concerned with evaluating the stress field at specific locations, irrespective of the geometry or loading conditions. But this definition does not consider the mutual influences of randomly distributed cracks which become significant when cracks coalescence and are finally forming macrocracks and faults. Consequently local analysis is not convenient for predicting, describing and analyzing of R.C. beams with various dramatic changes such as creating web openings, distributed cracks with different scales...etc, because of the wide range of modes of failure that can be produced under various loading conditions.

In the framework of continuum damage mechanics, different models, which account not only for the damage effects but also for the inelastic deformations have been proposed in literature. Among the models which take into account the nonlinear behaviour; Abu-Lebdeh et al. [7] formulated a plastic-damage model for concrete under cyclic loading, adopting a bounding surface concept. Luccioni et al. [8] proposed a thermodynamically consistent plastic and damage model, based on the classical plasticity theory and isotropic damage theory. Borino et al. [9] developed a thermodynamically consistent elastoplastic-damage model, which considers the coupling between the plasticity and damage internal variables. Madkour [10] has introduced a 3-D thermodynamic damage-plastic theory for plain concrete taking into account the plastic history of the material and the staggering influence between damage evolution and plastic phenomena. Moreover, anisotropic stiffness degradation and inelastic deformations are taken into account.

\section{SCOPE}

The mechanical properties and stress-strain response of reinforced concrete elements are mainly related to the micro defects in their internal structure. The nonlinear behaviour of such materials depends mainly on the initiation, evolution and coalescence of microcracks. The energy imparted to a solid during loading process in an isothermal process is either stored as elastic strain energy or dissipated through one of several permanent mechanisms or the micro structural rearrangement. The shortterm deformation and failure of concrete is governed by the evolution of cracks at microscopic and macroscopic level. The energy imparted during the nucleation and growth of microcracks and coalescence into macrocracks has been described with the help of continuum damage mechanics (CDM). CDM can overcome the numerical difficulties associated with the application of FEM, based on local theories. The framework of continuum damage mechanics has been introduced based on various theories such as thermodynamics of irreversible processes, the internal state variable theory and relevant physical considerations (such as the assumption of distributed 
microcracks, homogenization concept, the definition of micromechanical damage variable, the kinetic law of damage growth, nonlocal damage characterization and plasticity-damage coupling mechanism).

Therefore, in order to avoid modelling of localization bands or surfaces as weak or strong discontinuities, or to avoid enhancements by non-local kinematics, the use of damage mechanics will be introduced through the recent work. Consequently, in this paper a 'strain-based' damage model for reinforced concrete will be derived. The presented theory considers the nonlinear behaviour and the gradual degradation of the elastic stiffness caused by the existing damaged state and nucleation and growth of microcracks. The appropriate choice of expression for the Helmholz free-energy function is presented here. Based on this function a nonlinear constitutive equation and the evolution law for the damage state variable can be derived based on irreversible thermodynamics in order to analyze of the nonlinear behaviour of plain concrete. The predictions of the model are compared against the experimental data under uniaxial and biaxial compression loading. Validity of the proposed approach will be expanded through investigating the effect of rectangular web openings in the end zones of rectangular R.C. beams on their ultimate loading carrying capacity, deformation and stresses when subjected to static loading.

\section{NONLINEAR ELASTIC-DAMAGE THEORY}

It has been concluded that, non-linear finite element analysis provides a useful tool in understanding the behaviour of R.C. beams with openings and gives more realistic results than the linear analysis regarding concrete stresses, distribution of forces in steel bars, cracks and deformations [6]. Hence, the present article introduces a new theory taking into account the damage phenomenon and the elasticity in nonlinear regime with complete neglecting the plastic flow through the whole loading path.

The fundamental framework of the presented concept is the 'strain-based' nonlinear elastic damage theory. The model is based on dramatic modifications of the damageplastic coupled theory presented in $[10,11]$, that will be able to accurately reproduce the behaviour of reinforced concrete elements. Besides, the new model takes into account the specific characteristics of the dilatational response of concrete.

The starting point is modifying and developing of Helmholz-free energy function and the definition of internal thermodynamical variables to consider both, nonlinear elastic deformations and stiffness reduction. The basic assumptions of the new theory are:

- The material is assumed to exhibit completely elastic till failure,

- The plastic response of a damaged material under the applied stress is absent,

- Concrete is a stable material that the hardening behaviour is only under consideration with the recent work,

- The initial nonlinear behaviour is assumed to commence from the beginning of the loading bath,

- The main source of the nonlinearity is the stiffness degradation with further loading, 
- The damage threshold is based on the accumulated deformations and hence, the damage surface will be basically affected by the nonlinear elastic deformations.

The damage variable used in the recent work is the tensorial representation as in [10]. One of the basic assumptions in the presented new theory is that, the elastic matrix only depends on the current active damage tensor. Therefore, development of microcracks modifies the elastic properties of the material. Hence, the proposed elasticity tensor will be considered as a one-parameter damage-dependent elasticity tensor by tensorial algebra and thermodynamic requirements [11], as

$$
\tilde{D}=\lambda \phi_{i j} \phi_{k l}+\mu\left(\phi_{i k} \phi_{j k}+\phi_{i l} \phi_{j k}\right)
$$

The function $\phi_{i j}$ includes the active damage state $\tilde{\Omega}$ and a material constant $m$ to reflect the degree of the damage influence on the D-matrix and has been proposed, as

$$
\phi_{i j}=\delta_{i j}-m \tilde{\Omega}_{i j}-(1-m) \tilde{\Omega}_{i m} \tilde{\Omega}_{m j} \quad 0 \leq m \leq 1
$$

$\tilde{D}_{i j k l}$ is the fourth-order elastic and $\lambda, \mu$ are Lame's constants for virgin material.

\section{HELMHOLZ FREE-ENERGY FUNCTION}

The new proposed Helmholz free-energy function $\Psi$ as a thermodynamic potential, has been developed to be convex function of all observable and internal variables and will be divided into elastic potential functions and dissipative part, as follows:

$$
\Psi=\Psi^{e d}-\Psi^{\text {ned }}-\Psi^{\text {dila }}
$$

The term $\Psi^{e d}$ refers to the elastic strain energy stored in the material during the loading process. The thermodynamic elastic damaged free-energy $\Psi^{e d}[12]$ could be quadratic in strain tensor $\mathcal{E}$ and in active damage tensor $\tilde{\Omega}$, as:

$$
\Psi^{e d}=\frac{1}{2} \varepsilon_{i j}: \tilde{D}_{i j k l}: \varepsilon_{k l}
$$

This term has been adopted by most researchers with various damaged elasticity matrix expressions.

$\Psi^{\text {ned }}$ characterizes the new nonlinear Elastic-Damage potential function, and will refer to the strain energy dissipated in the material during the loading process, as well as to produce the nonlinear relation between the thermodynamic conjugate force $R$ and the active damage variable $\tilde{\Omega}$, as:

$$
\Psi^{n e}=\frac{1}{3} \varepsilon_{i j}: \tilde{D}_{i j k l}: \varepsilon_{k m}: \varepsilon_{m l}
$$


Dragon et al. [13] stated that "in the vicinity of zero strain, for the irreversible damaged materials, one may expect non-zero residual stress component to be generated. Inversely, for zero-stress, residual strain has been expected due to roughness and blocking on microcrack lips". Furthermore, this dilatancy term in the free-energy function has been based on the positive strain tensor to represent the damage growth which is depending on the hydrostatic stress to characterize the splitting mode in the level of free-energy function [10], as

$$
\Psi^{\text {dila }}=G . \tilde{\Omega}_{i j}: P_{i j k l}^{+}: \varepsilon_{k l}
$$

where $G$ is a material constant relevant to damage-induced residual stresses. $P_{i j k l}^{+}$is the fourth-order transformation tensor.

Substitution from Eqns. (4, 5 and 6) in Eqn. (3), the new developed postulated Helmholz free-energy function will be

$$
\Psi(\varepsilon, \Omega)=\frac{1}{2} \varepsilon_{i j}: \tilde{D}_{i j k l}: \varepsilon_{k l}-\frac{1}{3} \varepsilon_{i j}: \tilde{D}_{i j k l}: \varepsilon_{k m}: \varepsilon_{m l}-G . \varepsilon_{i j}: P_{i j k l}^{+}: \tilde{\Omega}_{k l}
$$

Total strain $\mathcal{E}$ is defined as for the damaged materials and active damage variable $\tilde{\Omega}$.

\subsection{The Constitutive Relation}

The constitutive equation and the kinetic equations will be derived by means of the well-established thermodynamic principles of irreversible processes. Clausius-Duhem inequality requires "the dissipation rate to be a non-negative quantity". The rate of energy dissipated will be derived, as

$$
\sigma_{i j} \cdot \dot{\mathcal{E}}_{i j}-\dot{\Psi} \geq 0
$$

Hence, the new constitutive relation can be established, as

$$
\sigma_{i j}=\frac{\partial \Psi}{\partial \varepsilon_{i j}}=\tilde{D}_{i j k l}: \varepsilon_{k l}-\tilde{D}_{i j k l}: \varepsilon_{k m}: \varepsilon_{m l}-G \cdot P_{i j k l}^{+}: \tilde{\Omega}_{k l}
$$

The previous stress-strain formulation has the ability to simulate the nonlinear behaviour through the nonlinear elastic relation, and the formation of the splitting-like cracks by the introduced dilatation concept, as well.

\subsection{Thermodynamic Damage Conjugate Force}

In Eqn. (7), a new general free-energy function has been developed including active damage tensor and the total deformations. The conjugate force is uniquely determined by the corresponding free-energy function. Hence, the thermodynamic damage force will be dependent on both active damage state and the nonlinear deformations. The second-order symmetric tensor $R_{i j}$ of the damage conjugate force will be derived, as 


$$
\begin{gathered}
R_{i j}=-\partial \Psi / \partial \tilde{\Omega}_{i j}=-\frac{\partial \Psi^{e d}}{\partial \tilde{\Omega}_{i j}}+\frac{\partial \Psi^{n e d}}{\partial \tilde{\Omega}_{i j}}+\frac{\partial \Psi^{d i l a}}{\partial \tilde{\Omega}_{i j}} \\
R_{i j}=(\lambda+2 \mu)\left[\varepsilon_{i j}: \phi_{i j}: N_{k l}: \varepsilon_{k l}-\varepsilon_{i j}: \phi_{i j}: N_{k l}: \varepsilon_{k m}: \varepsilon_{m l}\right] \\
+G \cdot P_{i j k l}^{+}: \varepsilon_{k l} \\
\partial \phi_{i j} / \partial \tilde{\Omega}_{i j}=-\left[m+2(1-m) \tilde{\Omega}_{i j}\right]=-N_{i j}
\end{gathered}
$$

\section{DISSIPATIVE POTENTIAL SURFACE}

According to irreversible thermodynamic theory for damaged materials, the evolutions of the internal variables are specified by a dissipation potential surface defined in the space of the driving forces conjugated to these internal variables [14]. The postulated potential surface which governs the direction of dissipative fluxes consists of the damage surface $F^{d}$ which is basically dependent on the thermodynamic damage force that is mainly derived from active damage tensor and the nonlinear deformations response. Hence, in the proposed model, the development of damage is dependent on both the current damage state and nonlinear deformations and the damage surface will be defined, as

$$
F^{d}=S^{d}\left[\sqrt{R_{i j} \cdot R_{i j}}+\operatorname{tr}(\tilde{\Omega}) \cdot \operatorname{tr}(R)\right]-\left(S_{0}+\Delta s\right)
$$

where $S^{d}$ is a material constant for controlling the damage surface size and $S_{0}$ represents the initial threshold of the damage evolution. The form of the damage surface presented in Eqn. (13) is similar to the function used in [15]. The new model differs from other approaches, not in presenting a new formulation for the damage surface, but in the new formulation of thermodynamic damage conjugate force including both the damage and nonlinear strain concept. With the help of the proposed potential damage surface, the following loading regions can be distinguished, as:

Initial Elastic regime: within the elastic loading process, there is no damage propagation of the microcracks. Consequently, the material can behave elastically.

$$
F^{d}-S_{0}<0 \Rightarrow F^{d}<S_{0}
$$

Subsequent Nonlinear damage regime: with a further loading process, an initial damage surface will be developed, and the microcracks will evolve.

$$
F^{d} \geq S_{0}
$$

Therefore, the evolution of initial flaws will be activated when the condition of damaging is met.

\section{DAMAGE EVOLUTION PROCESS}

Most observations from experimental investigations depicted that the damage evolution is accompanied by the developing of plastic strain and yield zone in the 
material [16]. In the recent work, the plastic response of a damaged material under the applied stress is completely absent for simplicity. The damage direction and growth are properly described by a damage dissipation surface, expressed in terms of the thermodynamic conjugate force. So the growth of damage internal variable will be, as

$$
\dot{\Omega}_{i j}=d z^{d} . \partial F^{d} / \partial R_{i j}
$$

The new proposed model will use the concept of intrinsic time to introduce the damage evolution law based on the total strain history, instead of the classical consistency condition, which is automatically satisfied in this case. The definition of the intrinsic time $z^{d}$ which is postulated, as

$$
d z^{d}=d \xi / f ; \quad f=1+\beta \xi+\frac{1}{2} \beta \xi^{2}
$$

where $f$ is a nonlinear hardening function and $\xi$ is the intrinsic measure, and it will be defined in the strain space according to the endochronic theory [17], as

$$
d \xi=\left|d e_{i j}\right|=\sqrt{d e_{i j} d e_{i j}} ; \quad e_{i j}=\varepsilon_{i j}-1 / 3 . \delta_{i j} \varepsilon_{k k}
$$

Therefore, in the proposed model, the damage threshold has been formulated basically on the total deformation history.

\section{Numerical Examples}

The present damage model represents the microcracks within a homogeneous matrix ignoring the differences in the elastic moduli between the aggregate pieces and mortar. Hence, without resorting to the multi-phase mixture theories and models, the proposed damage model characterizes the anisotropy nature of concrete due to the initiation and evolution of the microcracks. In the developed numerical modelling, Isoparametric Quadratic element (20 nodes element) have been used to simulate concrete in three dimensional regime; which is IPQS element in FINAL language [18], as in Fig. 1.

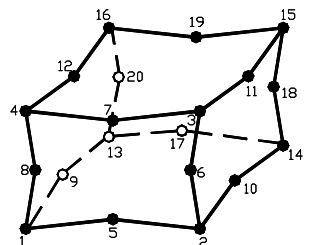

Figure 1: IPQS element (for Concrete)

In the following sections, some numerical examples applying the developed numerical model are presented. Such examples have been chosen to demonstrate the ability and limitations of the new presented model to simulate experimental results for the threedimensional fields under various loading conditions. 


\subsection{Uniaxial Compression Loading Case}

A numerical uniaxial compression test has been performed to indicate the main properties of the introduced damage model. The material is assumed to be initially undamaged. The simulation process has been carried out using standard cube $200 \mathrm{~mm}$ sides. Fig. 2 presents a comparison between the numerical and the experimental results conducted by Kupfer et al. [19] as a stress-strain relation. With this comparison with the experimentally stress-strain curve, it becomes obviously that, the peak stress and the corresponding strain are fairly estimated. Besides, the ascending branch up to the peak point shows good agreement. The correlation of the numerical data and experimental results turns out to be very good agreement, proving the validity of the developed model.

\subsection{Biaxial Compression Loading Case}

It is appropriate to incorporate the damage process into models characterizing the response of plain concrete to variable case of loading. Therefore, a biaxial numerical test has been performed for the same standard cube $200 \mathrm{~mm}$ sides. The numerical test has been preceded for the equal biaxial stresses and both stresses and strains at the point under the applied load have been compared with experimental results which provided by kupfer et al. [19], in Fig. 3.

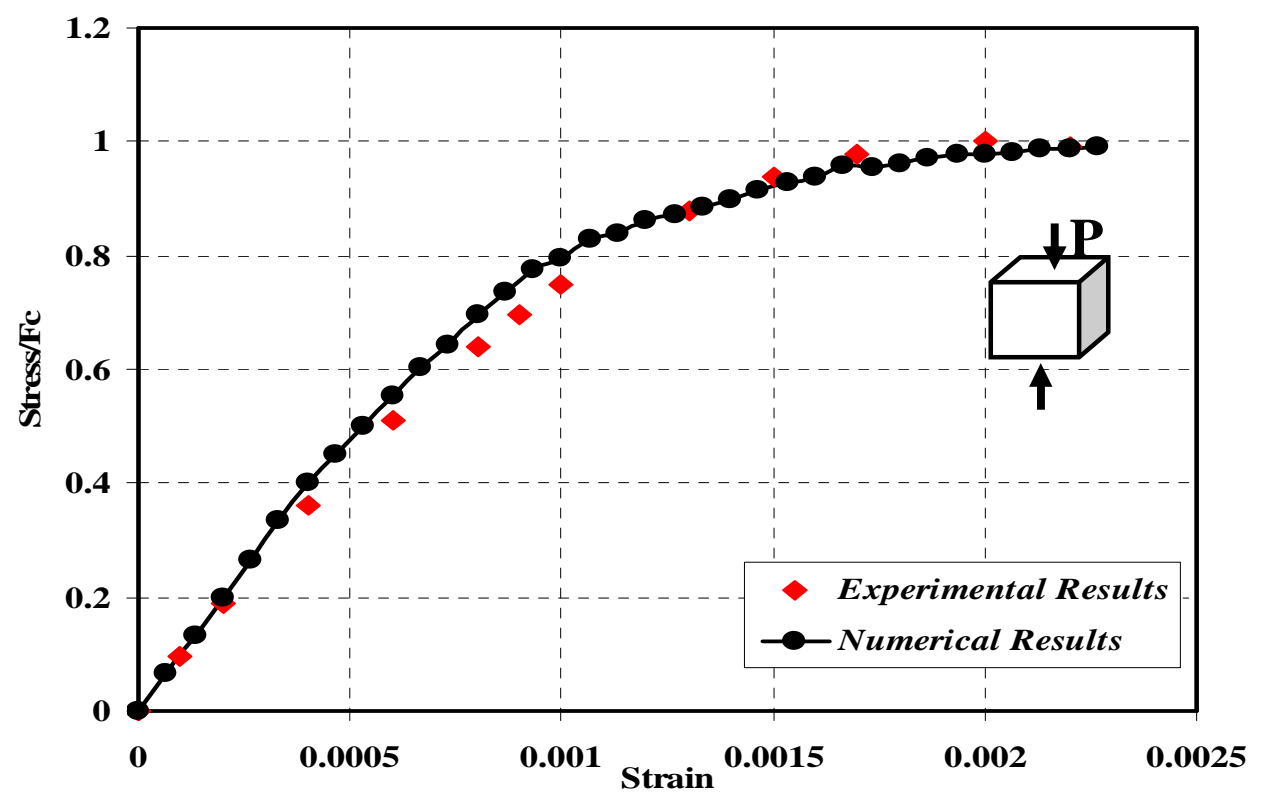

Figure 2: Stress-Uniaxial Strain Relation for Uniaxial Compression Loading 


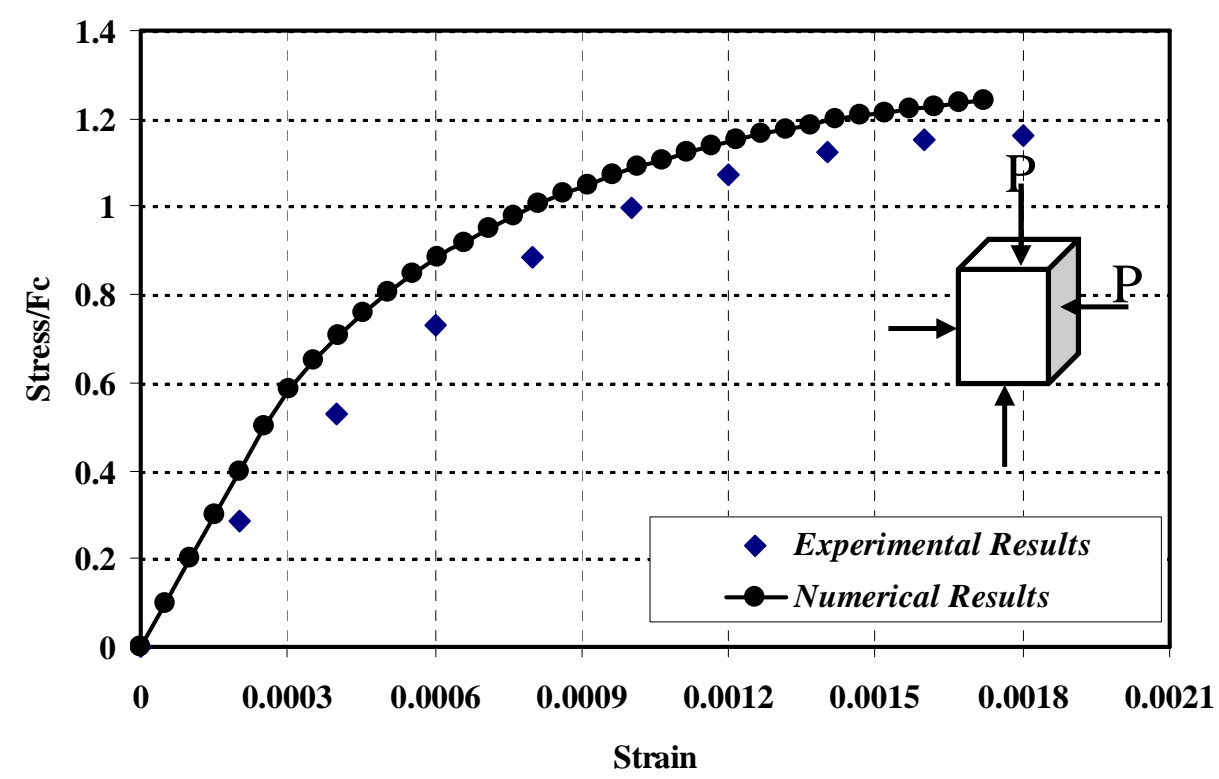

Figure 3: Stress-Uniaxial strain relation for biaxial compression loading

It becomes obvious that the peak stress and its corresponding strain are slightly overestimated numerically than that obtained experimentally (about $8 \%$ increase). However, the ascending branch up to the peak point shows good agreement. Consequently, the correlation of the analytical data and test data turns out to be considerably satisfied to be applied for plain concrete.

\section{APPLICATION TO R.C BEAMS WITH RECTANGULAR OPENINGS}

To evaluate the new model behaviour for complex concrete element model under loading conditions, numerical tests have been made for simple supported reinforced concrete beams without and with rectangular openings and their dimensions, as shown in Fig. 4, and Fig. 5, respectively. The numerical investigations have been performed with monotonically increasing vertical loading process on the top surface of the specimen. Table [1] lists the dimensions of the various R.C. beams and the resulting ultimate loads and modes of failure for each beam. All the beams have the same reinforcement details $3 \Phi 16$ as main reinforcement and $2 \Phi 10$ as top reinforcement.

Through numerical investigation, perfect contact has been assumed between concrete and reinforcement steel and the finite element used for concrete is Isoparametric Quadratic element (20 nodes element), as shown in Fig. 1. While the numerical modelling for steel reinforcement has been introduced as an elastic bar element (2 nodes element), which is BEAM 2 element in FINAL language [18], as in Fig. 6. 


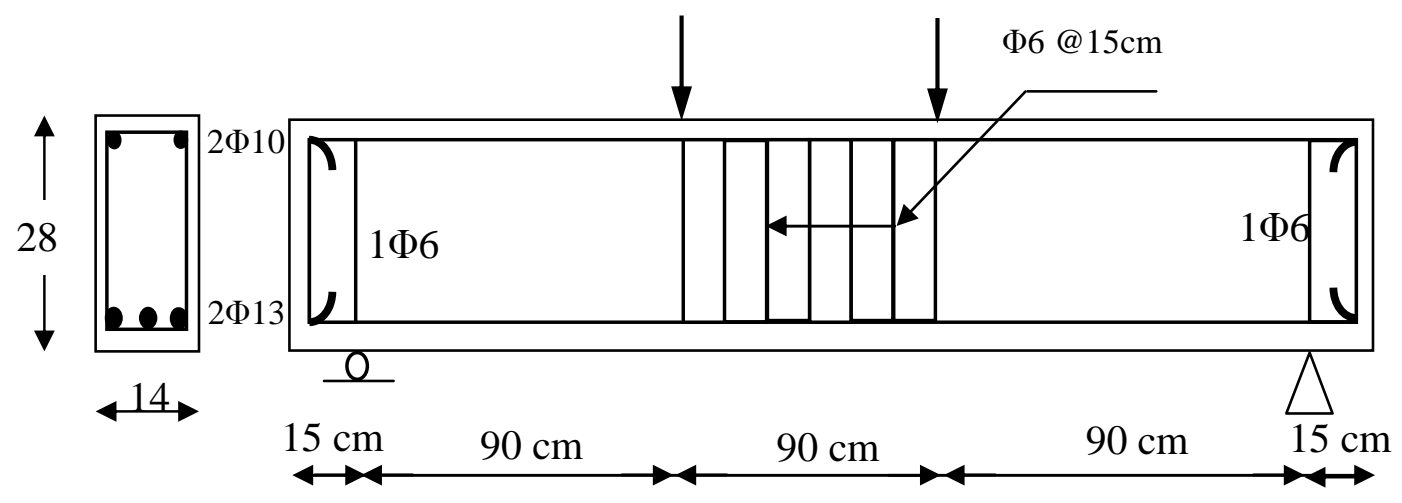

Figure 4: Schematically diagram for simple supported Solid Beam E1

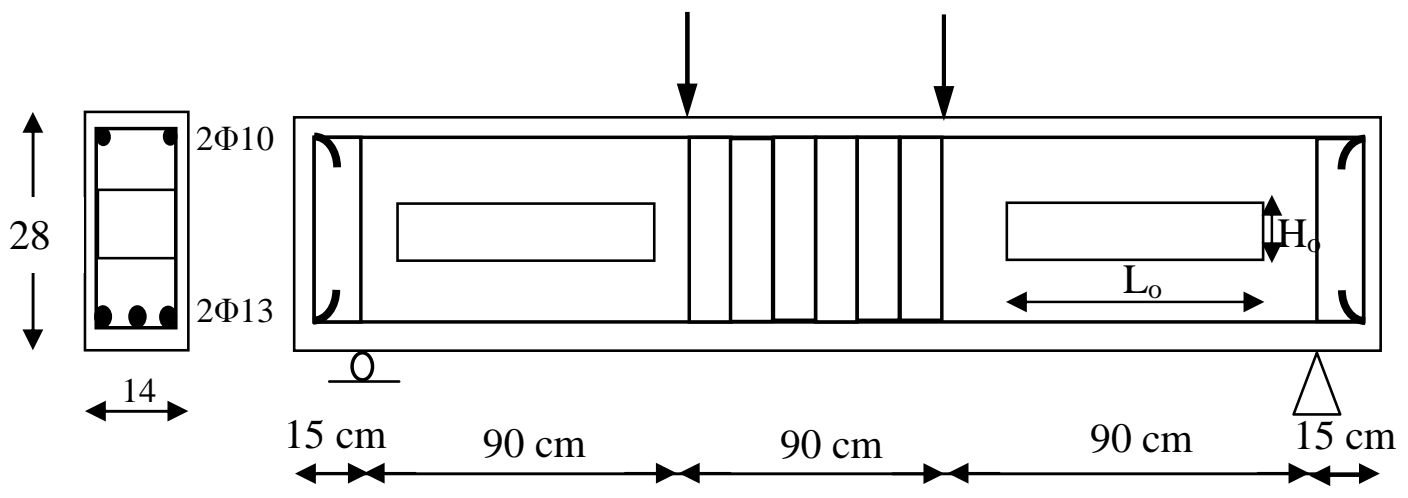

Figure 5: Schematically diagram for simple supported Beams E2 : E5

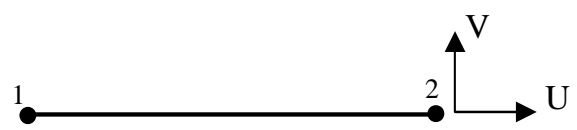

Figure 6: Beam 2 element (for Steel reinforcement)

Table 1: Details of tested R.C. Beams

\begin{tabular}{|c|c|c|c|c|c|c|c|}
\hline \multirow{2}{*}{$\begin{array}{c}\text { Beam } \\
\text { No }\end{array}$} & Span & Depth & $\mathrm{L}_{0}$ & $\mathrm{H}_{0}$ & \multicolumn{2}{|c|}{ Ultimate Load } & \multirow{2}{*}{\begin{tabular}{c} 
Modes of \\
\cline { 5 - 7 }
\end{tabular}} \\
\cline { 5 - 7 } & & & & Exp. & Num. & \\
\hline E1 & 300 & 28 & \multicolumn{2}{|c|}{ SOLID BEAM } & 9 & 9.85 & Flexure \\
\hline E2 & 300 & 28 & 60 & 8 & 3.8 & 4.1 & Corner Cracking \\
\hline E3 & 300 & 28 & 60 & 10 & 3.0 & 3.22 & Corner Cracking \\
\hline E4 & 300 & 28 & 60 & 12 & 2.2 & 2.3 & Corner Cracking \\
\hline E5 & 300 & 28 & 60 & 14 & 1.65 & 1.77 & Corner Cracking \\
\hline
\end{tabular}


Numerical results are compared with the observed response data for the tested reinforced concrete beams test conducted by [3]. The relation between load and vertical displacement at the mid-span point of the beams for both numerical and experimental tests are plotted in Figs. 7 to 11.

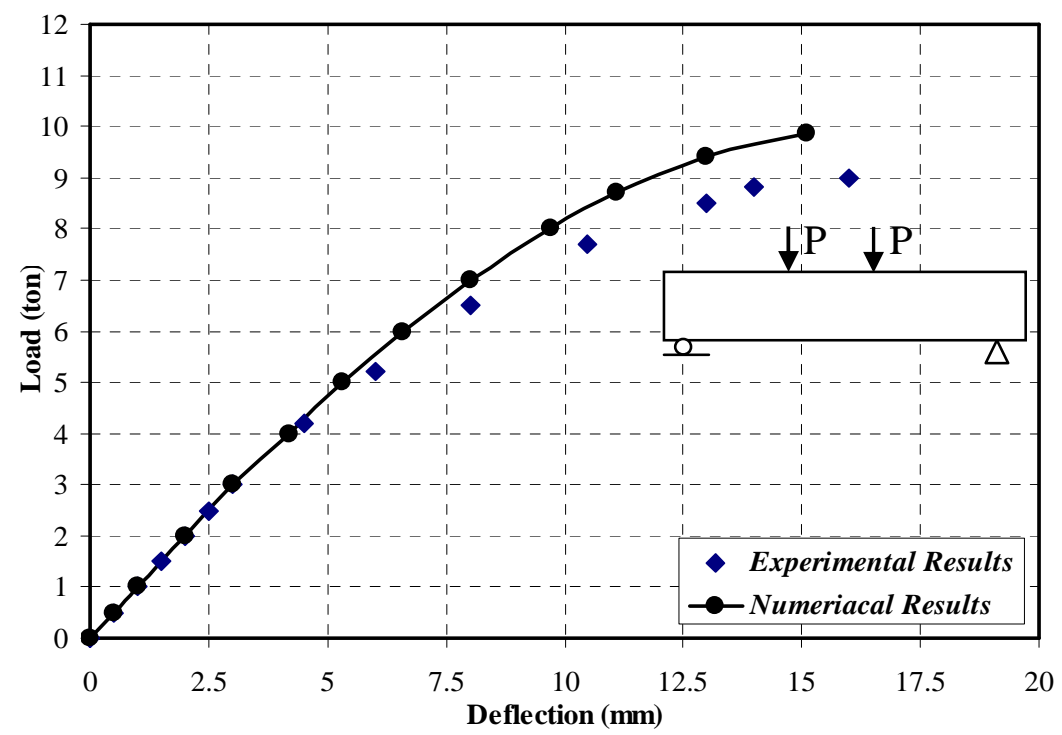

Figure 7: Load-Vertical deflection curve for simple supported beam E1

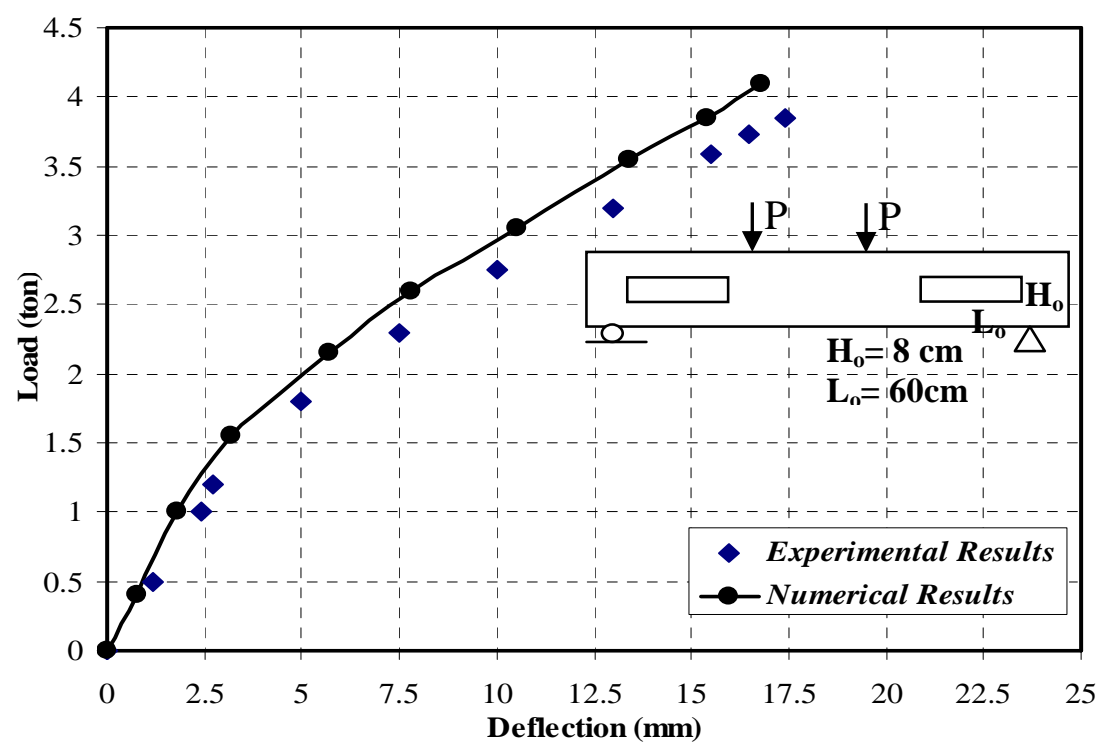

Figure 8: Load-Vertical deflection curve for simple supported beam E2 


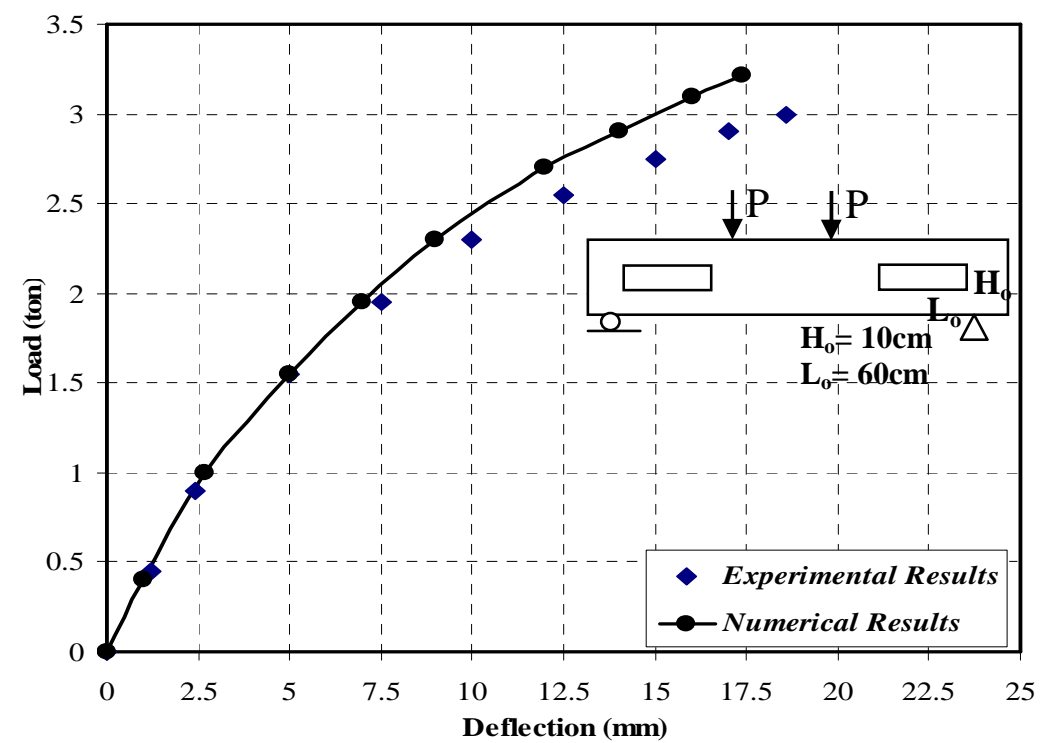

Figure 9: Load-Vertical deflection curve for simple supported beam E3

The correlation between the numerical results and the available experimental data obtained from the Load-Deflection relationships showed the ability of the new proposed theory to predict and describe the various features of the R.C. beams with different opening heights (i.e. the ultimate load, nonlinear behaviour, increasing the maximum deflection with increasing the opening height, and decreasing the ultimate load with increasing the opening height). It is worth to mention that the maximum difference between in predicting the ultimate load was about 10-12 \%, as shown in Fig. 12 which shows the comparison between the numerical and experimental results for the ultimate loads for the corresponding beams.

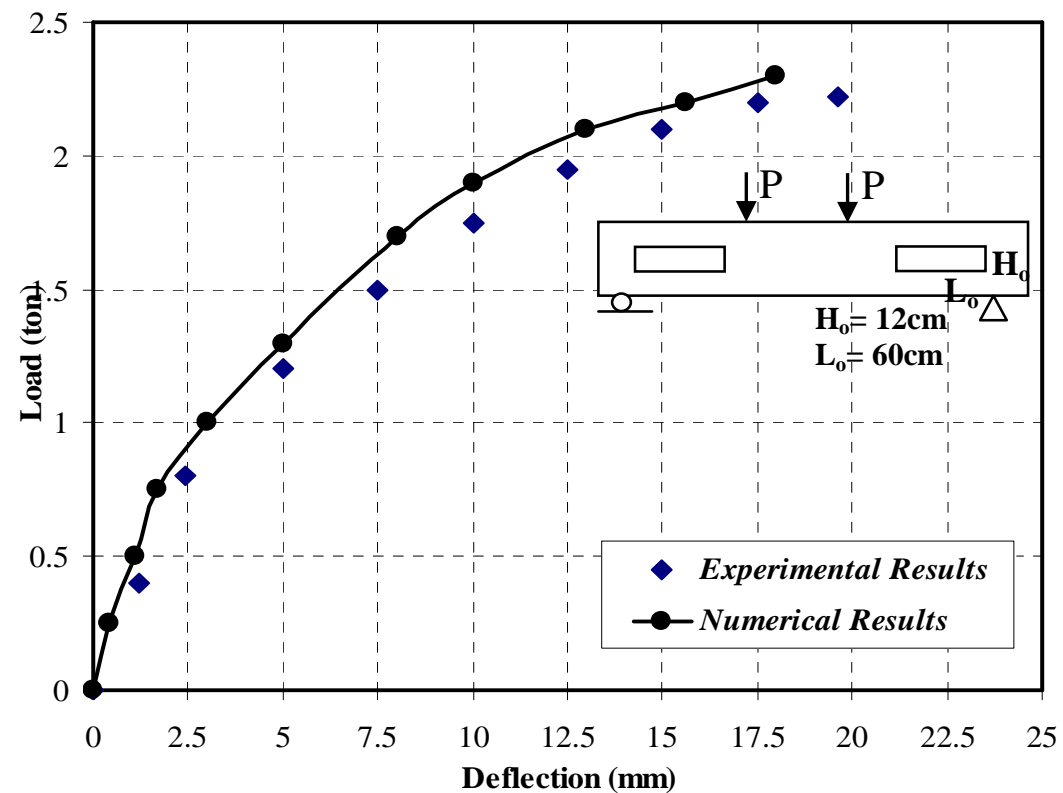

Figure 10: Load-Vertical deflection curve for simple supported beam E4 


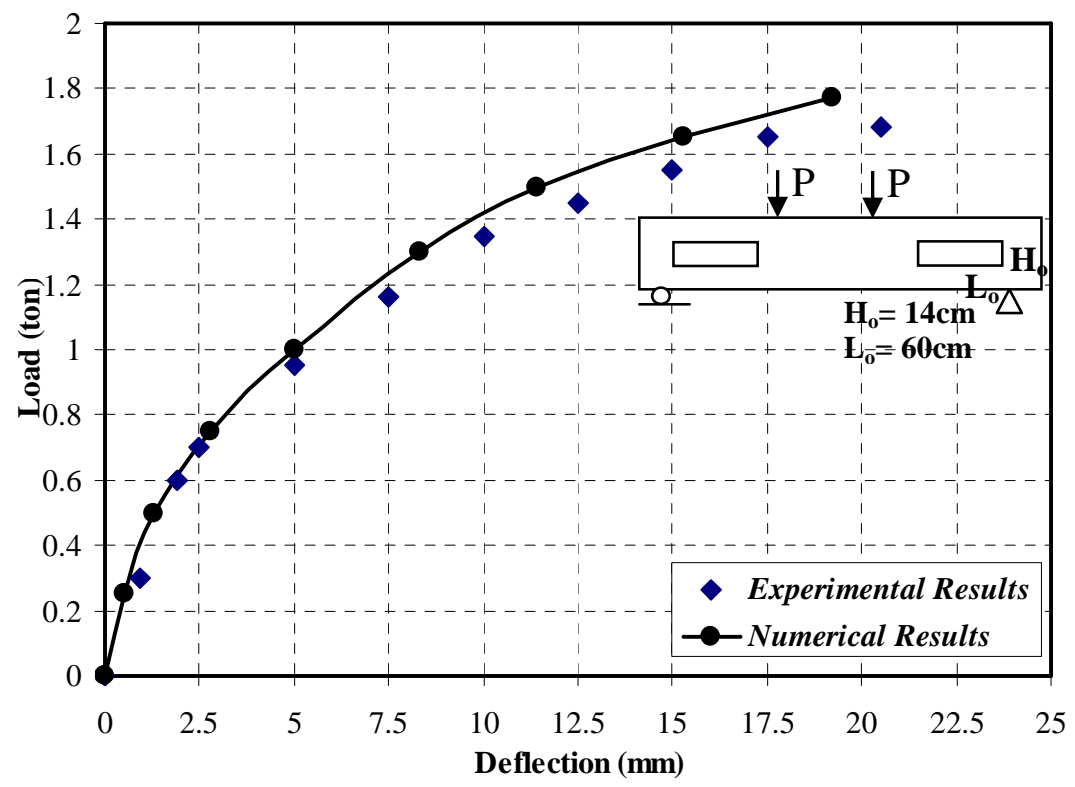

Figure 11: Load-Vertical deflection curve for simple supported beam E5

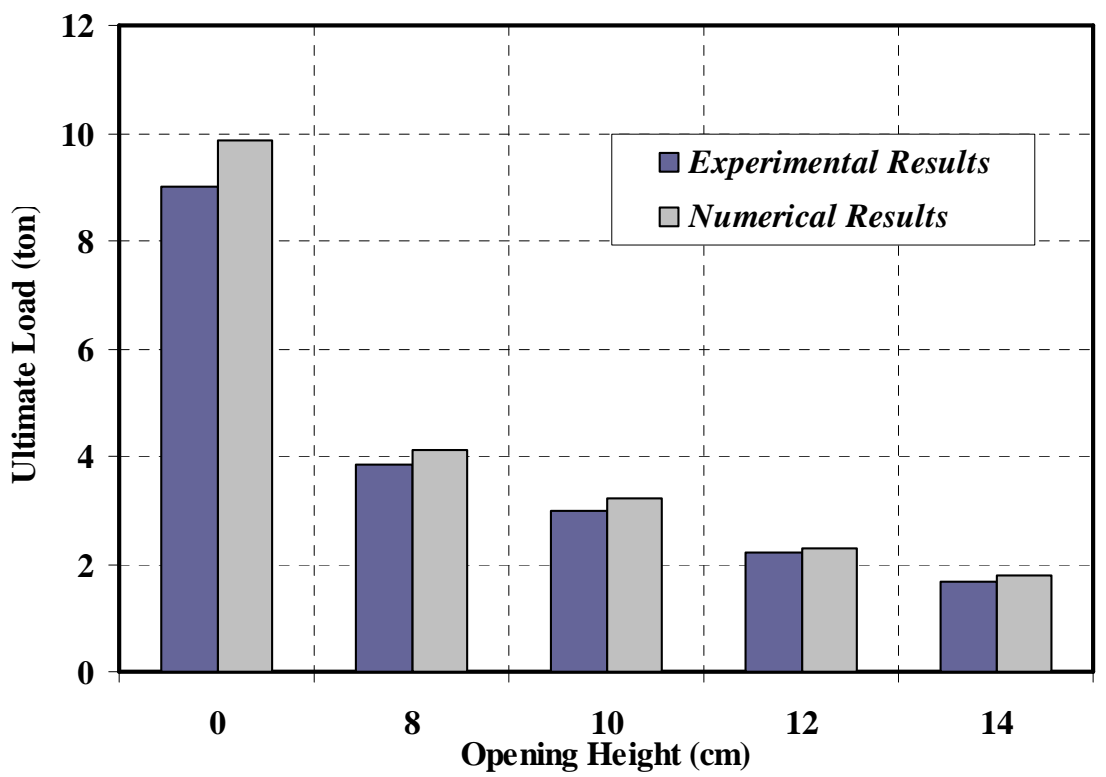

Figure 12: Ultimate Load-Opening Height curve

The increase in maximum deflection at the bottom of the reinforced concrete beams with the increase of the opening height for experimental and numerical results are, as shown in Fig. 13. The comparison indicates the decrease in numerical results about $8 \%$ than that obtained experimentally. The numerical differences in ultimate loads and maximum deflections may be due to the increase in rigidity of R.C. beams because of the perfect contact simulation between concrete and reinforcement steel. 


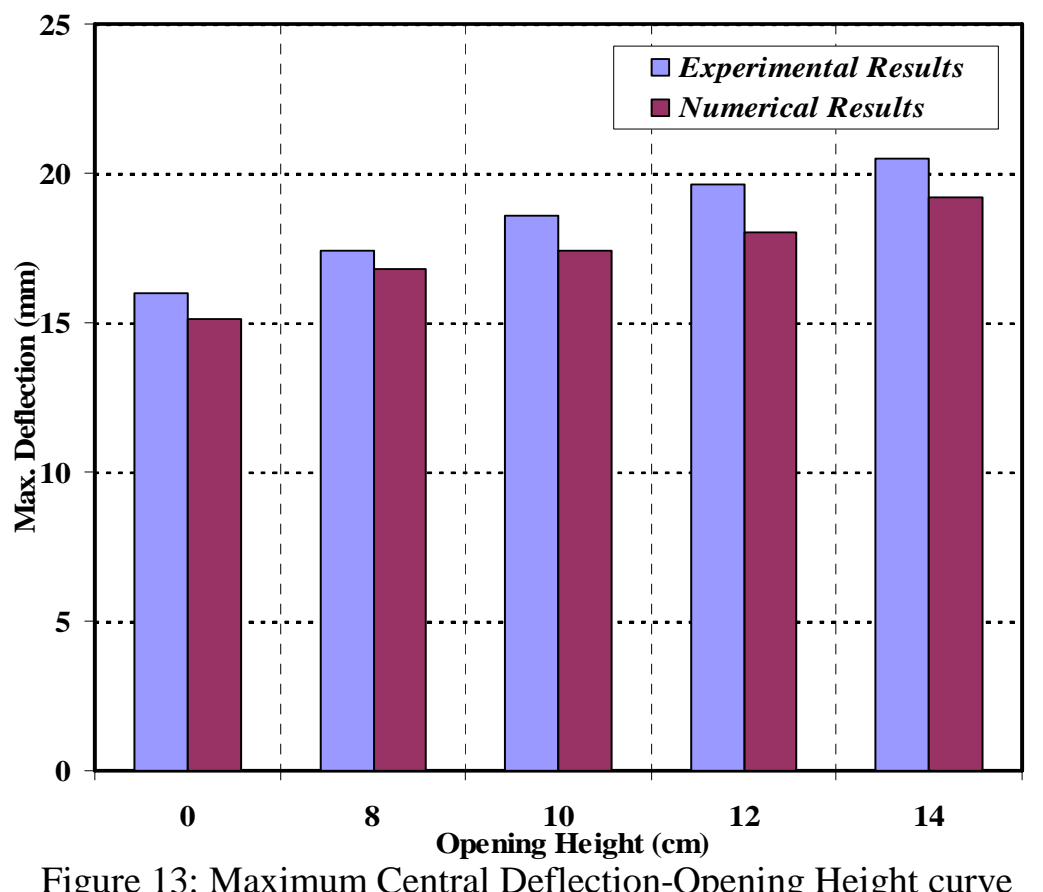

The figures from 14 to 18 show the damage propagation in the $X$-direction (the longitudinal axis of the beam) and the corresponding stress distributions at the failure state for the solid beams (E1) and for the R.C. beams with rectangular openings (E2 to E5) which monitoring the ability of the new theory to represent the deterioration state of the beams.
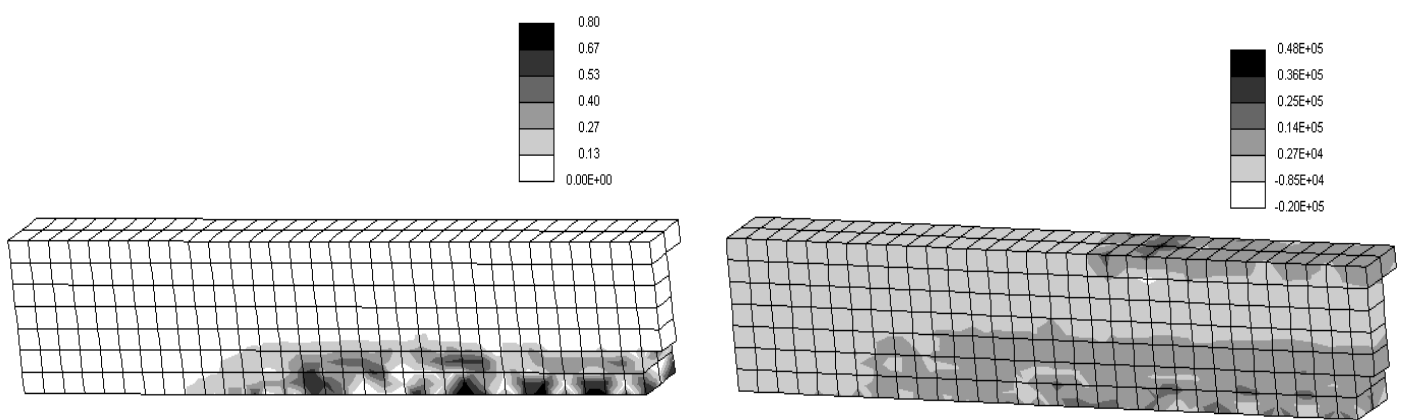

Figure 14: Damage and Stress distributions for Solid Beam E1 (at \% of the max. load) 

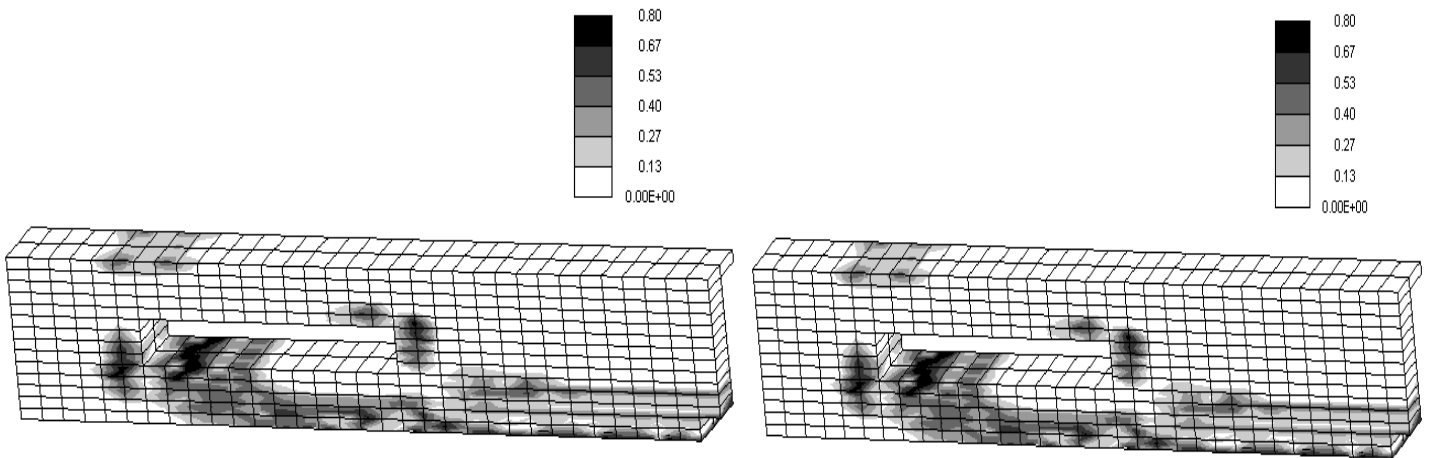

Figure 15: Damage and Stress distributions for R.C. Beam E2 (at $90 \%$ of failure load)
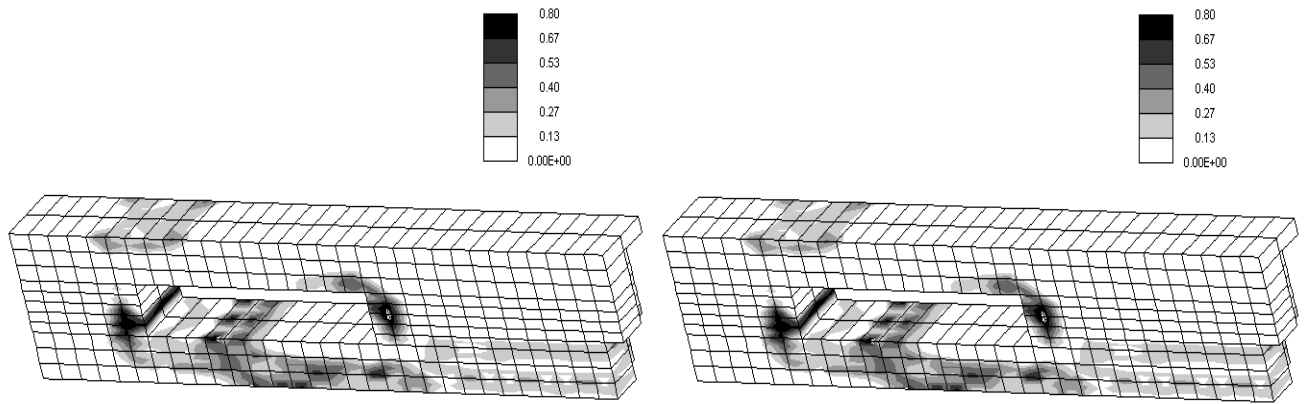

Figure 16: Damage and Stress distributions for R.C. Beam E3 (at $70 \%$ of failure load)
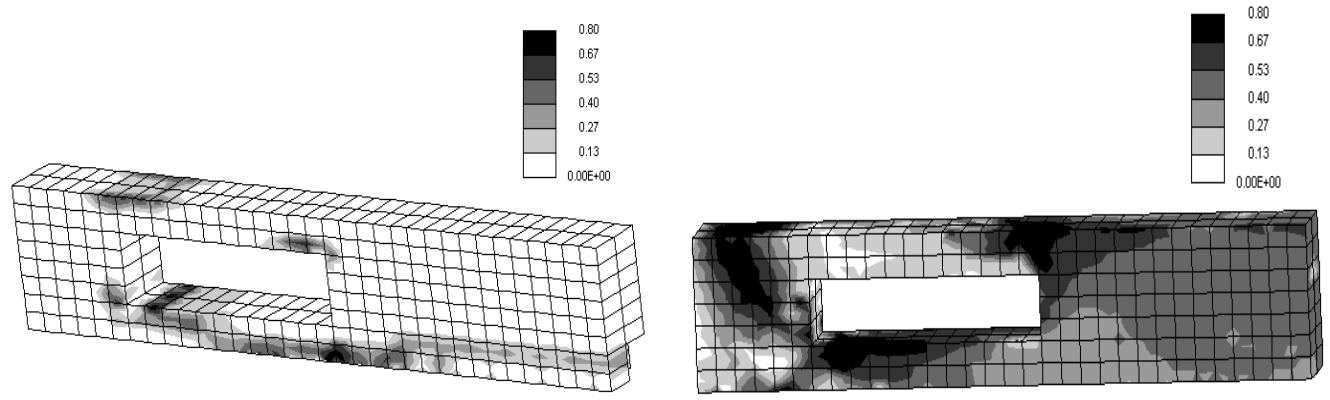

Figure 17: Damage and Stress distributions for R.C. Beam E4 (at $90 \%$ of failure load)
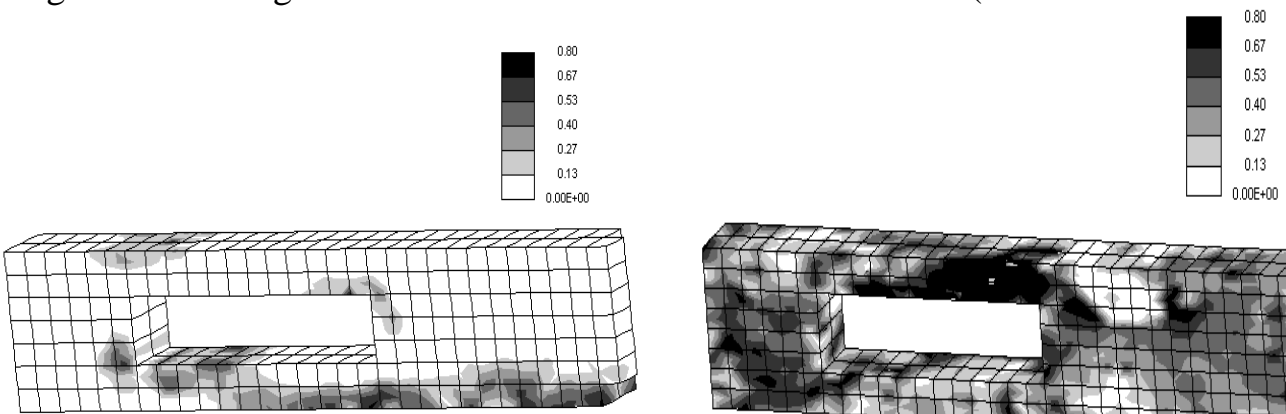

Figure 18: Damage and Stress distributions for R.C. Beam E5 (at $90 \%$ of failure load) 
In agreement with the experimental results documented in [3], the failure of Beam E1 the cracks were initiated at the bottom fibers subjected to high tensile stresses in the maximum moment region and propagates upwards. For beams E2 to E5, the cracks were completely different. Such cracks were initiated at the nearest corners to the support and the loading points. And the prominent mode of failure of these beams is corner cracking.

\section{CONCLUSIONS}

- The new theory for nonlinear elastic - damage behaviour was introduced to simulate the nonlinearity of the deteriorated concrete structures. The developed theory presents a rational constitutive model that considers the staggering process between nonlinear behaviour and damage evolution and both stored and dissipated energies in terms of the internal state variables based on irreversible thermodynamics.

- From the test results, it is easy to conclude that the provision of end rectangular opening in the shear zone of R.C beams increases the deflection, reduced the cracking and ultimate loads, changes completely the distribution of the stresses in the end of the beam and changes the mode of failure, which is in agreement with the experimental results of [3],

- The correlation of the analytical data and test data turns out to be very good agreement, proving the validity of the new presented model. The application to simple concrete elements (standard cube and simple supported beams) shows the great importance of this theory as a predicting tool for wide range of plain concrete and reinforced concrete beams with and without openings.

- The 3-D damage model is capable of describing the purely nonlinear elastic-damage behaviour for plain concrete and reinforced concrete, as well more than the linear methods, as concluded in [6].

- Eventually, application of the developed model has been implemented to relatively simple loading conditions and opening dimensions. Hence, it is necessary to extend the model for more complex loading conditions and opening features, as well.

\section{REFRENCES}

[1] Mohamed, A., "The effect of openings on structural elements with particular reference to reinforced concrete beams", M. SC. Thesis, Cairo University, 1962

[2]Nasser k. W., Acavlos A. and Daniel H. R.,"Behaviour and design of large openings in reinforced concrete beams", ACI journal,V.64, No. 3, pp. 152-163, March 1967.

[3] Hamdy H. A., "Behaviour of reinforced concrete beams with rectangular openings", M. Sc. Thesis, Assiut University, Egypt, 1978.

[4] Nassef, M. B., Ibrahim S., and El-Ghazouly, "Behaviour of Reinforced concrete beams with openings in shear zone", ESEC proceedings, V.3, Cairo University, Cairo, Egypt, 1985.

[5] Mansur, M. A, Huang L. M., Tan K. H., and Lee S., "deflections of reinforced concrete beams with web openings", ACI structural Journal, V. 69, No. 4, pp. 391397, July-August 1992. 
[6] Moussa, A., Mahmoud, A., Abdel-Fattah, W., and Abu-Elmaged, S., "Behaviour of R.C. deep beams with and without openings", In Proceedings of the $5^{\text {th }}$ International Alexandria conference for Structure and Geotechnical Engineering AICSGE5, 185-202. Alexandria, Egypt, 2003.

[7] Abu-Lebdeh, T.M., and Voyiadjis, G.Z., "Plasticity-damage model for concrete under cyclic multiaxial loading”. J. Eng. Mech. 119 (7), 1465-1484, 1993.

[8] Luccioni, B., Oller, S., and Danesi, R., "Coupled plastic-damaged model". Comput. Meth. Appl. Mech. Eng. 129, 81-89, 1996.

[9] Borino, G., Fuschi, P., and Polizzotto, C., "Elastic-plastic-damage constitutive models with coupling internal variables". Mech. Res. Commun. 23, 19-28, 1996.

[10] Madkour, H., "Thermodynamic Modelling of Damage-Plasticity for Concrete and its Application for Tunneling". Ph.D. Dissertation, University of Innsbruck, Austria, 2004.

[11] Madkour, H. and Swoboda, G., "Application of damage mechanics for plain concrete". Proceedings of The $3^{\text {rd }}$ Minia international Conference for Advanced Trends in Engineering (MICATE' 2005), April, 2005, Minia, Egypt.

[12] Chaboche, J. L., "Une loi differenetielle d'endommagement de fatigue avec cumulation non lineaire", Rev. Fr. Mec., 50, 51, 1974.

[13] Dragon, A., Pham D., Charlez P. and Shao J. F. "A Model of anisotropic damage by micro crack growth". In Proceedings of the International Symposium on Assessment and Prevention of Failure Phenomena in Rock Engineering, 71-78. Istanbul, Turkey, 1993.

[14] Murakami, S., Hayakawa K. and Liu Y. "Damage evolution and damage surface of elastic-plastic-damage materials under multiaxial loading", International Journal of Damage Mechanics, 7, 103-128 (1998).

[15] Madkour, H. and Swoboda, G., "Nonlinear Damage-Plasticity Analysis of Tunnel Intersections in Jointed Rock", Proceedings of $11^{\text {th }}$ IACMAG Conference, June, 2005, Torino, Italy.

[16] Madkour, H. and Swoboda, G., 2005. "Plastic Influence on Microcrack Growth for Concrete", Eleventh International colloquium on Structural and Geotechnical Engineering (11 ${ }^{\text {th }}$ ICSGE), 17-19 May, 2005, Cairo, Egypt.

[17] Valanis, K.C., "Fundamental consequences of a new intrinsic time measure, plasticity as a limit of the endochronic theory", Archives of Mechanics, 32, 171$191,1975$.

[18] Swoboda, G. "Program system FINAL- Finite element analyses program for linear and nonlinear structures”, Version 7.2, 2006.

[19] Kupfer, H., Hilsdorf H. K. and H. Rusch, "Behaviour of concrete under biaxial stresses", ACI Journal, 66, 656-666, 1969. 


\section{التمثيل ثلاثي الأبعـاد لانهيار كمـرات الخرسانة المسلحة ذات القتحـات بنــاعا على نظريـة المرونة اللاخطبه - التدمير}

الهدف من البحث هو تقديم نظرية التدمير -المرونة اللاخطيه ثلاثية الأبعاد لعناصر الخرسانة المسلحة. كما تم المزيد من التركيز قدم لتمثيل السلوك اللاخطى لكمرات الخرسانة المسلحة ذات الفتحـات بناء على قواعد الديناميكا الحرارية. المفهوم النظري المقترح قد أخذ في الاعتبار سلوك المرونة اللاخطى وحالة التدمير الحالية للخرسانة. أخيرا تم اختبار النمـوذج اللاخطى للخرسانة عن طريق العديد من النماذج العددية للتجارب المعلية من أجل تحليل سلوك كمرات الخرسانة المسلحة تحت تأثير الأحمال الأستاتيكية. مقارنـة النتائج النظرية بنتائج التجـارب المعمليـة من أجل التأكد من كفاءة النظرية المقترحة. وقد أتضح أتفاق نتائج النموذج المقترح على النتائج المعملية. 